\title{
Watermelon ripeness detector using near infrared spectroscopy
}

\author{
Edwin R. Arboleda*), Kimberly M. Parazo, Christle M. Pareja \\ Department of Computer and Electronics Engineering, College of Engineering and Information Technology, \\ Cavite State University \\ Indang, Cavite, Philippines 4122
}

\begin{abstract}
How to cite: E. R. Arboleda, K. M. Parazo, and C. M. Pareja, "Watermelon ripeness detector using near infrared spectroscopy," Jurnal Teknologi dan Sistem Komputer, vol. 8, no. 4, pp. 317-322, 2020. doi: 10.14710/jtsiskom. 2020.13744, [Online].
\end{abstract}

\begin{abstract}
This study aimed to design and develop a watermelon ripeness detector using Near-Infrared Spectroscopy (NIRS). The research problem being solved in this study is developing a prototype wherein the watermelon ripeness can be detected without the need to open it. This detector will save customers from buying unripe watermelon and the farmers from harvesting an unripe watermelon. The researchers attempted to use the NIRS technique in determining the ripeness level of watermelon as it is widely used in the agricultural sector with high-speed analysis. The project was composed of Raspberry Pi Zero $W$ as the microprocessor unit connected to input and output devices, such as the NIR spectral sensor and the OLED display. It was programmed by Python 3 IDLE. The detector scanned a total of 200 watermelon samples. These samples were grouped as $60 \%$ for the training dataset, $20 \%$ for testing, and another $20 \%$ for evaluation. The data sets were collected and are subjected to the Support Vector Machine (SVM) algorithm. Overall, experimental results showed that the detector could correctly classify both unripe and ripe watermelons with $\mathbf{9 2 . 5} \%$ accuracy.
\end{abstract}

Keywords - watermelon; near-infrared spectroscopy; support vector machine; ripeness level

\section{INTRODUCTION}

Watermelon, with the scientific name Citrullus lanatus, is a non-climacteric fruit [1]. It is popularly cultivated and consumed in most tropical areas of agricultural countries, especially in Asia. Watermelon growth reports for almost 9.5 percent of the world's total vegetable production [2]. Every year, 111 million metric tons of watermelon were consumed in the world [3]. Unlike other fruits, watermelon does not tend to ripen after picking, so it is not good to harvest it unripe and let it ripen on the counter. Because after removing from the vine, the fruit does not develop external color or increase sugar content [4], [5].

There are various types of watermelon, some of which are red flesh and yellow flesh. For this study, the watermelon variety tested by the device is the "Sweet

\footnotetext{
${ }^{*}$ Correspondence author (Edwin R. Arboleda)

Email: edwin.r.arboleda@cvsu.edu.ph
}

Gold" watermelon. This variety is oblong, has a bright green outer rind with a yellowish ground spot, and its flesh is yellow. This variety weighs between 2 to 4 kilograms.

The traditional method of determining watermelon's maturity is by thumping with a finger, which gives a hollow sound as an indication of maturity [6]. Farmers and watermelon retailers use this traditional method of determining the ripeness level of the watermelon. However, these decisions lead to subjective interpretation and ensure that enormous quantities of watermelons are harvested too early or too late on schedule [7]. Another method of determining watermelon's maturity is by cutting it and look for its seeds. The immature watermelon (unripe) has shrunken white seeds shown in Figure 1(a). Ripe watermelon has most of the seeds black shown in Figure 1(b) [8]. However, this approach is not practical since the watermelon needs to be cut.

Different types of researches have been done about ripeness detection by its acoustic properties [9], capacitance sensing [10], dynamic technology using complex analysis including Laser Doppler Vibrometry (LDV) [11]-[13], image processing [14], and spectroscopy including visible light (VIS) [15], and near-infrared (NIRS) [16], [17]. All of the mentioned studies are about the classification of fruit ripeness using non-destructive methods, which is also incorporated in this study using near-infrared spectroscopy.

Over the centuries, technological advancements are applied in agriculture, and near-infrared spectroscopy is increasingly used. This method is relatively inexpensive, non-destructive, and can measure several properties concurrently [17]. It can also be used to evaluate multiple components in just a single scan. The

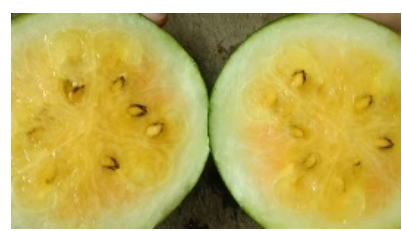

(a)

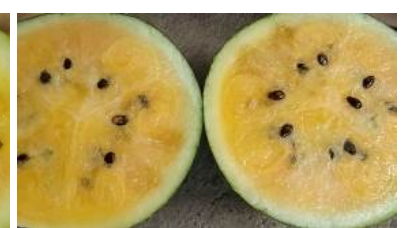

(b)
Figure 1. Ripeness level of watermelon by its seed color: a) unripe watermelon, and b) ripe watermelon 
significant advantage of NIRS is that it is typically not necessary to prepare a sample, so the analysis is straightforward and very quick (between 15 and 90 seconds) [18]. The NIRS spectrum assessment does not allow samples' grounding because the spectra of light show some different properties in another sample when the light passes through it [19].

Infrared spectrometry is a technique commonly used by researchers to examine food and agricultural products [20]. In addition to that, near-infrared (NIR) spectroscopy is based on electromagnetic (EM) radiation absorption at wavelengths between 700 and $2,500 \mathrm{~nm}$ [21]. During industrial processing, the reflectance measurement technique would be useful in the quality analysis of watermelon fruit. It can be performed online in packing houses and on-farm [22].

There is a need for automated detection techniques for this study using the reflectance measurements of watermelon to an algorithm by using machine learning. Machine learning algorithms can be used to predict long-term data that can be used in this analysis, including the Support Vector Machine (SVM) [23]. MATLAB software has the Classification Learner app that can help build the model of the proposed device.

According to past research, SVM provides the highest accuracy as it has a higher generalization of durability and a more robust classifier than other algorithms [24]. The classification to separate data classes using SVM is used in many different applications. Andika [25] used the SVM method to classify all texture features' value extracted from the image ROI Kintamani inscription. The SVM models are usually used to classify one or two classes [26].

This study focused on the design and develop a device for watermelon ripeness using NIR spectroscopy. The device only classifies whether the watermelon is unripe or ripe using the SVM algorithm. By measuring light scattered off and through the watermelon, NIR reflectance spectra can be used to quickly determine the watermelons' internal content properties [27]. Nearinfrared spectroscopy was used in gathering the reflectance measurements. These data sets were subjected to the SVM algorithm to create a trained model. The study uses Raspberry Pi Zero WH to process the data collected, control the device's operation, and display the output data on a display screen.

\section{RESARCH METHODS}

\section{A. Preparation of watermelon samples}

A total of 200 watermelon samples were gathered and utilized for this study, containing 100 unripe watermelons and 100 ripe ones. These samples were grouped as $60 \%$ for the training dataset, $20 \%$ for testing, and another $20 \%$ for evaluation. The training and testing datasets were taken from Nanay Zeny's farm, while the latter was obtained from Nanay Girly's farm. These farms were both located at Calibuyo, Tanza, Cavite.
Table 1. Bill of materials for the construction of the device

\begin{tabular}{crrr}
\hline \multirow{2}{*}{ Qty } & \multicolumn{1}{c}{ Description } & \multicolumn{2}{c}{ Cost (P) } \\
\cline { 3 - 4 } & & \multicolumn{1}{c}{ Unit } & \multicolumn{1}{c}{ Total } \\
\hline 1 & Raspberry Pi Zero W & 2419.00 & 2419.00 \\
& Kit & & \\
1 & NIR Spectral Sensor IC & 1400.00 & 1400.00 \\
1 & OLED display & 300.00 & 300.00 \\
1 & Powerbank & 700.00 & 700.00 \\
1 & Slider wwitch & 10.00 & 10.00 \\
2 & Push button & 25.00 & 50.00 \\
1 & Acrylic chassis & 4000.00 & 4000.00 \\
& Miscellaneous & 1000.00 & 1000.00 \\
& Total cost & & 9879.00 \\
\hline
\end{tabular}

For the training datasets, 100 samples each of predetermined unripe and ripe watermelons were scanned by the device. The scan was done by placing the prototype at the center of the oblong watermelon. After scanning, the watermelon is cut in two to determine whether it is according to the predetermined class of ripe or unripe. After the training datasets programmed to the classifier, the prototype was tested to a whole watermelon; again, it was cut in two to determine if the samples were correctly classified.

\section{B. Materials}

Table 1 shows the material and the total expenses incurred in the device's construction, including the chassis' cost and labor. The total cost is 9,879.00 Philippine pesos, which is cheaper than commercially available NIRS devices wherein the cheapest costs 250,000 pesos.

Raspberry Pi Zero W served as the brain of the watermelon ripeness detector. Spectral sensor is a complete single-chip spectrometer designed to identify wavelengths in 6 near-IR channels at 610, 680, 730, 760, 810, and $860 \mathrm{~nm}$ of light. Out of six NIRS channels, only four were utilized for the prototype. These are 730, 760, 810, and $860 \mathrm{~nm}$ because only these four channels exhibit pronounces differences between unripe and ripe watermelon, thus excluding 610 and 680 nm. A 128x64 OLED LCD screen with 1.3 inch blue display and a module I2C interface for Raspberry Pi was used to show the ripeness level of watermelon, whether it is unripe or ripe, and a power bank with 5000 mAh was used to power the device.

\section{Design and construction of the watermelon ripeness detector}

Figure 2 shows the circuit diagram of the system. The individual components were connected to the microprocessor using jumper wires. The NIR sensor and buttons were the input devices to the Raspberry Pi, while the LCD was the output device. The sensor and OLED display used similar pins: SCA, SDA, 3.3V, and GND, and were connected directly to the Raspberry Pi. The start button was connected on GPIO17 and GND, 
while the shutdown button for raspberry pi was on GPIO27 and GND. The on/off switch was in series with the cathode of the battery.

Figure 3 shows the construction of the watermelon ripeness detector. Two switches were used in the device. First, a slider switch is placed on the right side. This switch turns the device on and off. Second, a normally open push button switch that was placed beside the LCD so that the user may freely operate the device. Clicking this button leads to the functioning of the spectral sensor. Inside the prototype's casing contains Raspberry Pi Zero W, NIRS Spectral Sensor, and power the supply. The spectral sensor was placed near the tip of the device to read the reflected light signals from the watermelon. As the sensor's processor, Raspberry $\mathrm{Pi}$ Zero $\mathrm{W}$ classified the watermelon according to its ripeness level.

Finally, LCD that was placed facing the user displays the ripeness level of the watermelon. The whole device was made-up of an acrylic board to support its portability and compactness goals. The researchers also considered the size of the electronic components that were used. The dimensions of the device in different perspective views were shown in Figure 4.

\section{Detection operation}

Initially, the device is manually turned on via SHUTDOWN switch, which boots up the Raspberry Pi Zero W, and the program for the system automatically starts. Also, the display turns on and prompts the message 'start' when everything was initialized. To classify, the user will press a START button. This button pressing triggers the program's code to turn on the sensor and start measuring the reflected signals and

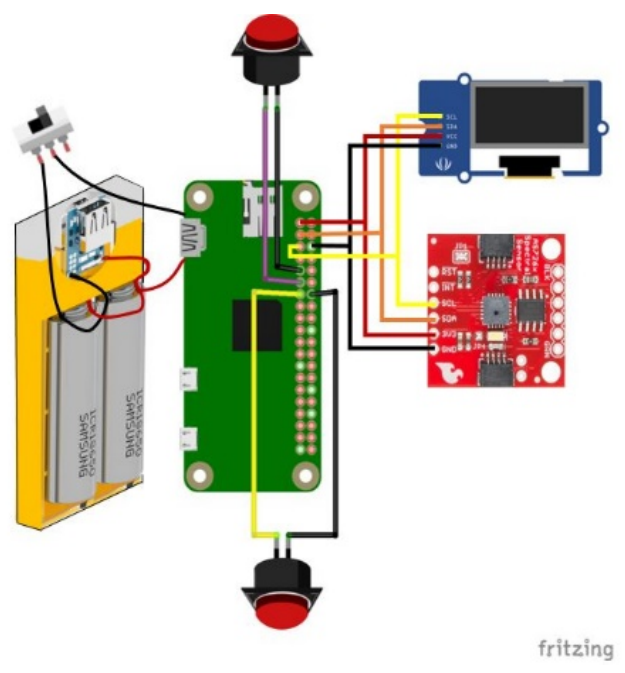

Figure 2. Pictorial circuit diagram of the device

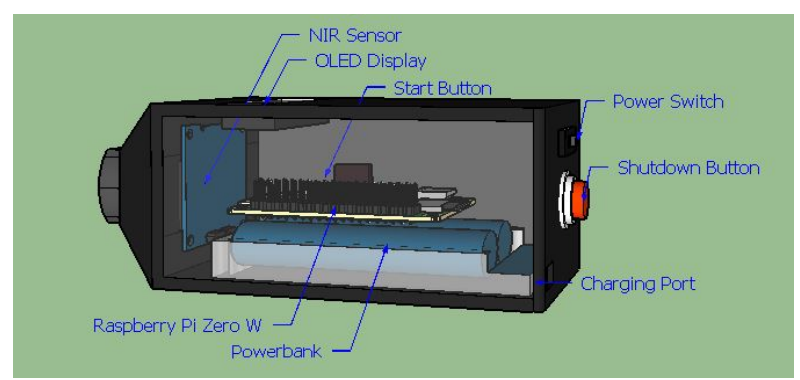

Figure 3. Construction design of the device

save it to a CSV file. This data is fed on a pre-trained SVM classifier. The result from the classification is displayed on the LCD. This process can be repeated multiple times until the user switched off the device.

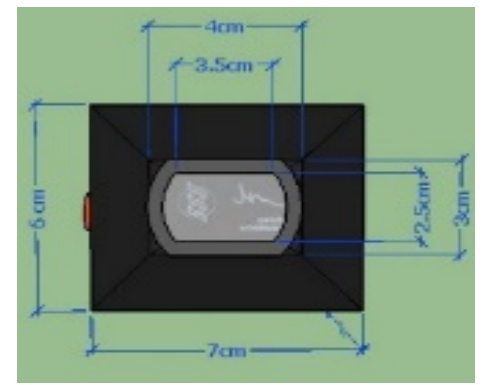

(a)

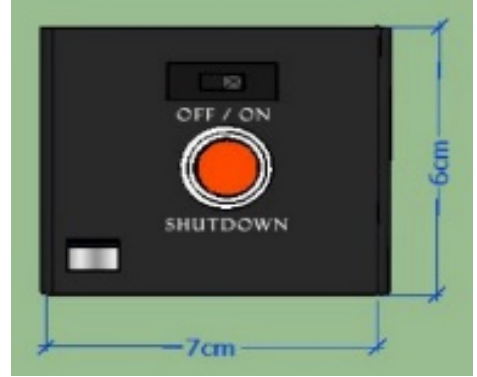

(c)

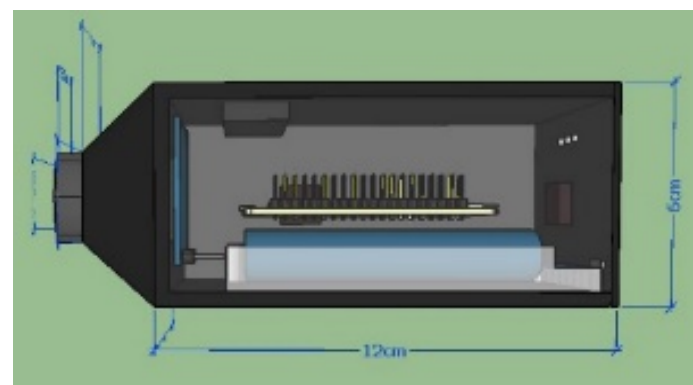

(b)

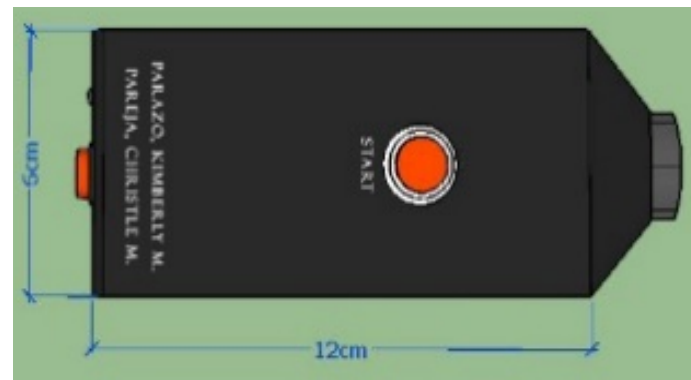

(d)

Figure 4. Dimensions of the device from a different perspective: a) front view, b) left side view, c) back view, d) right side view 


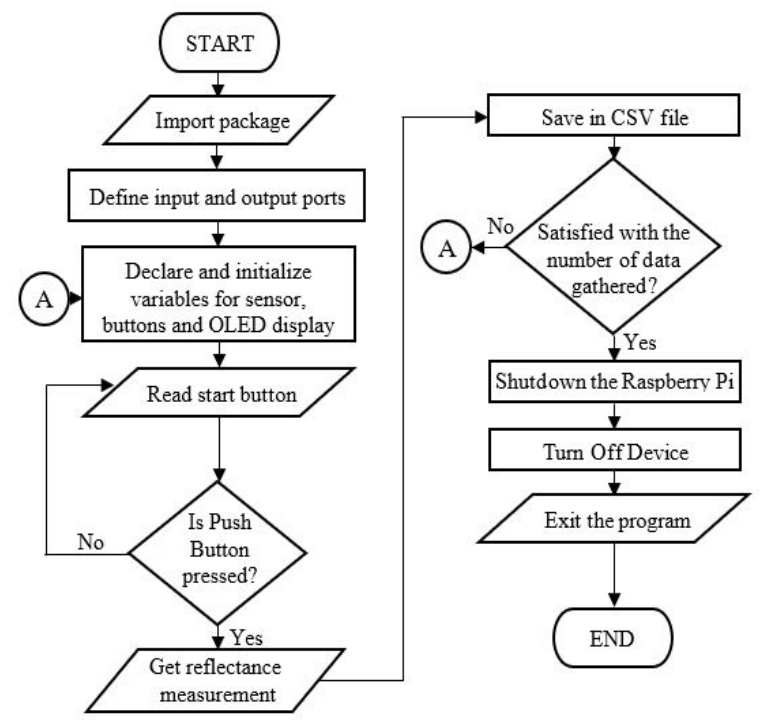

Figure 5. Program flowchart of the system

\section{E. Development of the Python program for the system}

The program that ran on the Raspberry $\mathrm{Pi}$ was written in Python language using the pre-installed Python 3 IDLE in the Raspbian OS. First, necessary packages were imported, and variables were defined. The script had imported the essential library to control the sensor and OLED display using the Raspberry Pi. General Purpose Input/Output (GPIO) pins were declared, and variables were then initialized.

Figure 5 shows the flowchart in developing the source code that controls the program's flow for initialization up to sending the data to the SVM classifier. The watermelon ripeness detector uses the SVM classifier. Figure 6 shows the process of developing the SVM model that would classify the ripeness level of watermelon based on its reflectance measurements. Training datasets were imported and undergone preprocessing. Then, these were fed to a support vector machine classifier. The network was fit and had undergone validation. If the result of it is not satisfactory, the network parameters will be changed and undergo retraining. If the model prediction accuracy is acceptable, then we can now detect the ripeness level of watermelon.

Finally, the model was deployed to the Raspberry Pi Zero W. This model was used to classify watermelon from its reflectance. This model was integrated into the program of the system.

\section{RESULTS AND DISCUSSION}

Figure 7 shows the actual design of the watermelon ripeness detector. The circuit connections were inside of it and can be opened by removing the screws on the corner. The sensor and OLED display were secured by its cover to protect it from the dirt.

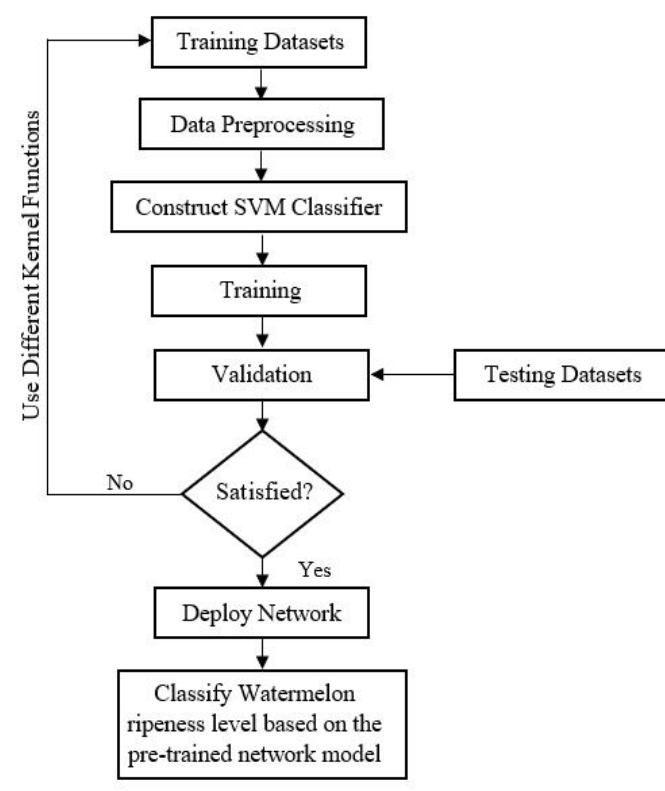

Figure 6. General process in building an SVM model

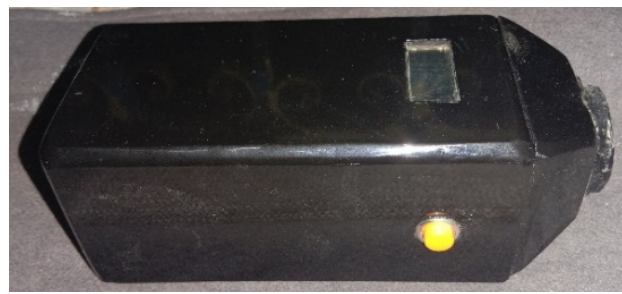

(a)

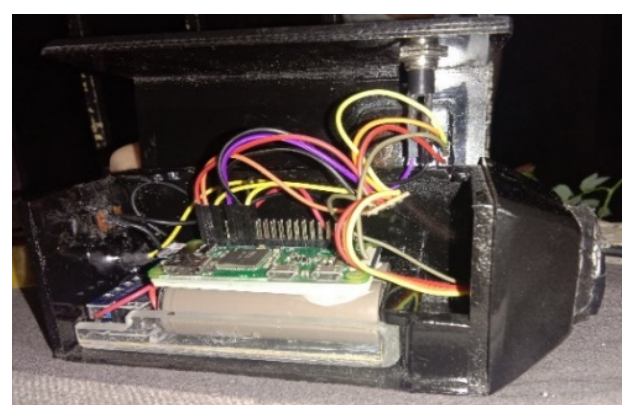

(b)

Figure 7. Actual view of the device: a) external view, adn b) internal view

Figure 8 shows the training datasets. It was plotted on a 2-dimensional axis using $730 \mathrm{~nm}$ and $760 \mathrm{~nm}$ as the $\mathrm{X}$ and $\mathrm{Y}$-axis, respectively. It can be seen that the data were linearly separable. Figure 8(b) shows the statistical information of the dataset. Unripe watermelons have values less than 100 , while the ripe has higher than it.

The SVM model was subjected to numerous training, validation, and testing. Moreover, as a result, an accuracy of 95.6 percent from the 40 samples in the testing dataset was obtained. Then, the model was already integrated into the system. 


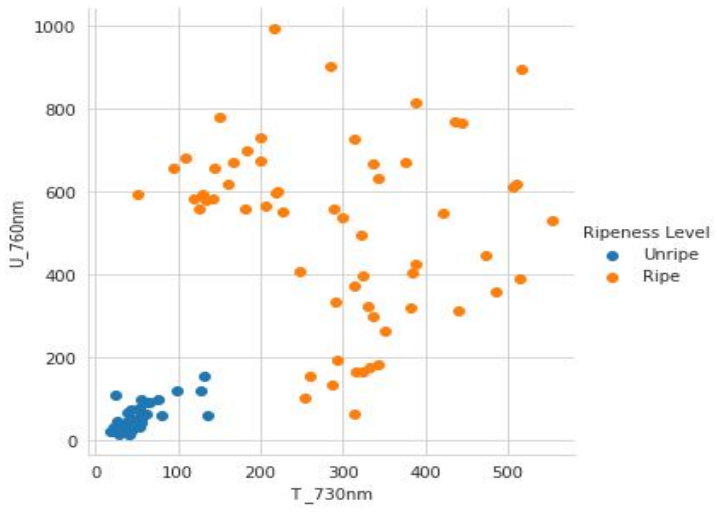

(a)
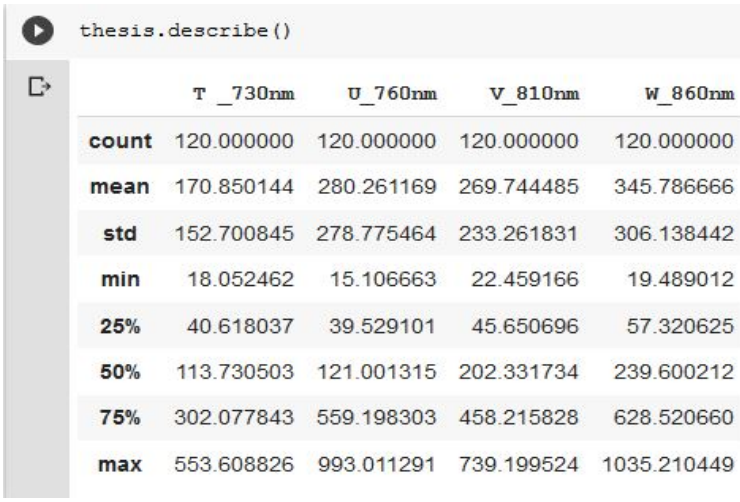

(b)

Figure 8. Training dataset: a) scatter plot, and b) statistic information

Table 2. Evaluation result summary

\begin{tabular}{cccc}
\hline \multirow{2}{*}{ Actual } & \multicolumn{2}{c}{ Predicted class } & \multirow{2}{*}{ Sensitivity } \\
\cline { 2 - 3 } & Unripe & Ripe & \\
\hline Unripe & 17 & 3 & 0.85 \\
Ripe & 0 & 20 & 1 \\
Precision & 1 & 0.87 & $\mathbf{0 . 9 2 5}$ \\
\hline
\end{tabular}

The evaluation was conducted at Bailen, Cavite. Table 2 shows the summary result of the evaluation from 40 watermelon samples with different ripeness levels. The samples were first tested by the device, then opened it to verify the result. Thirty-seven watermelons were classified correctly. Therefore, the device accuracy is 92.5 percent.

Table 3 compares the percentage of classification accuracy of this study to other studies in determing watermelon ripeness. It shows that among nondestructive techniques in classifying ripe and unripe watermelon, this study has the highest percentage in classification accuracy of $92.5 \%$. This result means that NIRS frequencies of $730,760,810$, and $860 \mathrm{~nm}$ are a promising technology for watermelon ripeness classification, as in [15]-[17], [19]-[22], [27] for other non-destructive detectors. This paper's main contribution is the proof that a low-cost NIRS IC using its four frequencies can be used for determining the ripeness of watermelon. Moreover, the SVM classifier has proven its effectiveness in discriminating unripe from ripe watermelon using the four NIRS frequencies as inputs [26].

\section{CONCLUSION}

The detector can detect the watermelon ripeness level using spectroscopy with trained SVM model integration on Raspberry Pi Zero W. The device was able to identify the ripeness levels of watermelon by placing it on the ground spot or yellowish part of the watermelon. The device accuracy has met the desired objectives of about $92.5 \%$. Therefore, NIRS frequencies of $730,760,810$, and $860 \mathrm{~nm}$ are a promising technology for watermelon ripeness classification.
Table 3. Comparison of classification accuracy in determining watermelon ripeness

\begin{tabular}{lcc}
\hline \multicolumn{1}{c}{ Methods } & Citation & Accuracy (\%) \\
\hline Accoustic signals & {$[9]$} & 89 \\
Image processing & {$[14]$} & 90 \\
Visible light & {$[15]$} & 75 \\
This study & - & $\mathbf{9 2 . 5}$ \\
\hline
\end{tabular}

\section{ACKNOWLEDGMENT}

The authors would like to express their sincerest appreciation to faculty members, advisers, technical critics, and Cavite State University administrators. Mr. Domingo Austria, an agriculturist at the Department of Agriculture, helped us in searching watermelon farm in Tanza, Cavite. Nanay Zeny and Nanay Girly Mintu, owners of the farm, for the warm welcome and allow the authors to gather watermelon samples to train and evaluate data sets in their fields.

\section{REFERENCES}

[1] A. Salman-Minkov and T. Trebitsh, "Characterization of watermelon fruitlet development," in EUCARPIA Meeting on Genetics and Breeding of Cucurbitaceae, Avignon, France, May 2008, pp. 609-614.

[2] S. Guo et al., "Comparative transcriptome analysis of cultivated and wild watermelon during fruit development," PloS One, vol. 10, no. 6, pp. 1-21, 2015. doi: 10.1371/journal.pone.0130267

[3] H. Q. Tian, Y. B. Ying, H. S. Lu, X. P. Fu, and H. $\mathrm{Y}$. Yu, "Measurement of soluble solids content in watermelon by Vis/NIR diffuse transmittance technique," Journal of Zhejiang University Science $B$, vol. 8, no. 2, pp. 105-110, 2007. doi: 10.1631/jzus.2007.B0105

[4] M. Cantwell and T. V Suslow, "Cabbage: Recommendations for maintaining postharvest quality,” Department of Vegetable Crops, University California, Davis, CA95616, 2001.

[5] D. Markham, "How to tell if a watermelon is ripe," TreeHugger, 2015. [online]. 
[6] P. Perkins-Veazie, J. C. Beaulieu, and M. Siddiq, "Watermelon, cantaloupe and honeydew," in Tropical and Subtropical Fruits, USA: Wiley, pp. 549-568, 2012. doi: 10.1002/9781118324097.ch28

[7] M. L. Stone, P. R. Armstrong, X. Zhang, G. H. Brusewitz, and D. D. Chen, "Watermelon maturity determination in the field using acoustic impulse impedance techniques," Transactions of American Society Agricultural and Biological Engineers, vol. 39, no. 6, pp. 2325-2330, 1996. doi: $10.13031 / 2013.27743$

[8] Y. X. Zhang, J. L. Han, and W. Yao, "Nondestructive watermelon maturity detection by acoustic response," in 2nd International Conference on Information Engineering and Computer Science, Wuhan, China, Dec. 2010, pp. 1-4. doi: 10.1109/ICIECS.2010.5677746

[9] W. Zeng, X. Huang, S. M. Arisona, and I. V. McLoughlin, "Classifying watermelon ripeness by analysing acoustic signals using mobile devices," Personal and Ubiquitous Computing, vol. 18, no. 7, pp. 1753-1762, 2014. doi: 10.1007/s00779-0130706-7

[10] M. Soltani, R. Alimardani, and M. Omid, "Prediction of banana quality during ripening stage using capacitance sensing system," Australian Journal of Crop Science, vol. 4, no. 6, pp. 443447, 2010.

[11] R. Abbaszadeh, A. Rajabipour, M. Mahjoob, M. Delshad, and H. Ahmadi, "Evaluation of watermelons texture using their vibration responses," Biosystems Engineering, vol. 115, no. 1, pp. 102-105, 2013. doi: 10.1016/j.biosystemseng.2013.01.001

[12] D. Cui, Z. Gao, W. Zhang, and Y. Ying, "The use of a laser Doppler vibrometer to assess watermelon firmness," Computers and Electronics in Agriculture, vol. 112, pp. 116-120, 2015. doi: 10.1016/j.postharvbio.2006.06.007

[13] S. Terasaki, N. Sakurai, J. Zebrowski, H. Murayama, R. Yamamoto, and D. J. Nevins, "Laser Doppler vibrometer analysis of changes in elastic properties of ripening 'La France' pears after postharvest storage," Postharvest Biology and Technology, vol. 42, no. 2, pp. 198-207, 2006. doi: 10.1016/j.postharvbio.2006.06.007

[14] N. A. Syazwan, M. S. B. S. Rizam, and M. T. Nooritawati, "Categorization of watermelon maturity level based on rind features," Procedia Engineering, vol. 41, pp. 1398-1404, 2012. doi: 10.1016/j.proeng.2012.07.327

[15] M. M. Abdullah, N. E. Abdullah, H. Hashim, A. A. A. Rahim, C. George, and F. A. Igol, "Various grades of red flesh watermelon ripeness based on NIR and VIS reflectance measurement," in IEEE Student Conference on Research and Development, Pulau Pinang, Malaysia, Dec. 2012, pp. 250-255. doi: 10.1109/SCOReD.2012.6518648

[16] X. Tao and Y. Bao, "Measurement of sugar content of watermelon using near-infrared reflectance spectroscopy in comparison with dielectric property," in Fourth International Conference on Photonics Imaging Biology and Medicine, Tianjin, China, Oct. 2006, 60473V. doi: 10.1117/12.710921

[17] M. Bhunase and S. Patil, "Near infrared spectroscopy for fruit quality analysis," International Journal of Engineering and Research Technology, vol. 10, no. 1, pp. 1-15, 1998.

[18] B. G. Osborne, "Near-Infrared Spectroscopy in food analysis," in Encyclopedia of Analytical Chemistry: Applications, Theory and Instrumentation. Wiley, 2000, pp. 1-14. doi: 10.1002/9780470027318.a1018

[19] E. R. Arboleda, "Discrimination of civet coffee using near infrared spectroscopy and artificial neural network," International Journal of Advanced Computer Research, vol. 8, no. 39, pp. 324-334, 2018. doi: 10.19101/IJACR.2018.839007

[20] K. H. S. Peiris, G. G. Dull, R. G. Leffler, and S. J. Kays, "Near-infrared spectrometric method for non-destructive determination of soluble solids content of peaches," J. Am. Soc. Hortic. Sci., vol. 123, no. 5, pp. 898-905, 1998.

[21] H. S. El-Mesery, H. Mao, and A. E. F. Abomohra, "Applications of non-destructive technologies for agricultural and food products quality inspection," Sensors (Switzerland), vol. 19, no. 4, pp. 1-23, 2019. doi: 10.21273/JASHS.123.5.898

[22] K. Flores, M. T. Sánchez, D. C. Pérez-Marín, M. D. López, J. E. Guerrero, and A. Garrido-Varo, "Prediction of total soluble solid content in intact and cut melons and watermelons using near infrared spectroscopy," Journal of Near Infrared Spectroscopy, vol. 16, no. 2, pp. 91-98, 2008. doi: 10.3390/s19040846

[23] I. Fitriyaningsih and Y. Basani, "Flood prediction with ensemble machine learning using BP-NN and SVM," Jurnal Teknologi dan Sistem Komputer, vol. 7, no. 3, pp. 93-97, 2019. doi: 10.14710/jtsiskom.7.3.2019.93-97

[24] N. Nurajijah and D. Riana, "Algoritma naïve Bayes, decision tree, dan SVM untuk klasifikasi persetujuan pembiayaan nasabah koperasi syariah," Jurnal Teknologi dan Sistem Komputer, vol. 7, no. 2, pp. 77-82, 2019. doi: 10.14710/jtsiskom.7.2.2019.77-82

[25] I. G. Andika, "Klasifikasi citra HSV aksara kuno pada prasasti tembaga Kintamani menggunakan GLRCM dan SVM," Jurnal Teknologi dan Sistem Komputer, vol. 8, no. 2, pp. 94-99, 2020. doi: 10.14710/jtsiskom.8.2.2020.94-99

[26] M. R. Mustaffa, L. W. Yee, L. N. Abdullah, and N. A. Nasharuddin, "A colour-based building recognition using support vector machine," Telkomnika (Telecommunication Computing Electronics and Control), vol. 17, no. 1, pp. 473480, 2019. doi: 10.12928/telkomnika.v17i1.11609

[27] P. Sirisomboon, "NIR Spectroscopy for quality evaluation of fruits and vegetables," Materials Today: Procedings, vol. 5, no. 10, pp. 2248122486, 2018. doi: 10.1016/j.matpr.2018.06.619 